\title{
ĐÁNH GIÁ KẾT QUẢ TRUNG HẠN PHẪU THUẠT BẮC CẦU CHỦ VÀNH Ở BỆNH NHÂN HẸP BA THÂN ĐỘNG MẠCH VÀNH TẠI TRUNG TÂM TIM MẠCH BỆNH VIẾN E
}

Nguyễn Công Hựu*, Đoàn Quốc Hung**, Nguyễn Hũu Ước**, Lê Ngọc Thành*

\section{TÓM TẮT}

Trong thời gian từ tháng $2 / 2010$ đến $12 / 2014$ có 93 bệnh nhân được phẫu thuật. Tuổi trung bình $65,34 \pm 7,65$ (44 - 83), nữ chiếm $22,66 \%$. Phương pháp mổ bắc cầu chủ vành kinh điển với tuần hoàn ngoài cơ thể, cặp động mạch chủ làm ngừng tim, bảo vệ cơ tim bằng dung dịch máu ấm. Khám lại, đánh giá kết quả trung hạn dựa trên triệu chứng lâm sàng, siêu âm tim qua thành ngực, chụp kiểm tra cầu nối bằng chụp động mạch vành chọn lọc hoặc chụp cắt lớp vi tính đa dãy. 87/93 bệnh nhân sống ra viện. Thời gian theo dõi trung bình $52,13 \pm 14,79$ tháng $(25-79)$, mất theo dõi: 2 bệnh nhân. Tử vong trong thời gian theo dõi $9(10,58 \%)$ (6 do nguyên nhân tim mạch), còn sống 76. Lâm sàng: 13 bệnh nhân đau ngực lại, không có trường hợp nào suy tim NYHA III, IV. Siêu âm tim so sánh tại thời điểm trước mổ, ra viện và khám lại: rối loạn vận động vùng giảm, chỉ số EF cải thiện có ý nghĩa ở nhóm bệnh nhân EF thấp tại thời điểm ra viện, số bệnh nhân có rối loạn vận động vùng tăng lên trong thời gian theo dõi. Tổng số 225 cầu nối được chụp kiểm tra: còn thông 141(62,67\%), hẹp tắc: $84 / 225(37,33 \%)$. Cầu nối vào ĐMV hẹp $\geq$ $95 \%$ trước mổ có tỉ lệ tắc hẹp thấp hơn ( $\mathrm{p}=$ 0,009). Mạch ghép động mạch ngực trong có tî lệ cầu nối còn thông cao nhất, không có sự khác biệt giữa mạch ghép động mạch quay và tĩnh mạch hiển lớn $(\mathrm{p}<0,05)$. Bệnh nhân sau bắc cầu chủ vành cải thiện về lâm sàng. Các biến cố tim mạch chính hay gặp trong thời gian theo dõi sau mổ: tử vong, hẹp tắc cầu nối phải can thiệp lại. Mạch ghép động mạch ngực trong là cầu nối có chất lượng tốt nhất.

\section{SUMMARY}

Evaluating mid-term results of coronary artery bypass graft surgery for three-vessel disease patients at Cardiovascular Center, E Hospital

From 2/2010 to 12/2014, there were 93 patients underwent CABG surgery. The mean age was $65.34 \pm 7.65$ years old (ranged from 44 to 83 years), female accounted to $22.66 \%$. The classic CABG surgery with extra-corporeal circulation, aortic cross clamp to perform cardioplegia, myocardial protection using warm-blood solution. On follow-up visit, evaluation of the mid-term results after surgery based on clinical symptoms, trans-thoracic echocardiography, bypass graft assessment by selective percutaneous coronary angiography or multi-slice computed tomography angiography. 87/93 patients survived until discharge. Mean follow-up duration was $52.13 \pm$ 14.79 months (ranged from 25 - 79 months), loss of follow-up: 2 patients. There were 9 deaths, accounted to $10.58 \%$, during follow-up (5 was due to cardiovascular diseases), 76 patients survived. Clinical: 13 patients had recurrent angina, there was no cases with heart failure NYHA class III, IV. Comparison between echocardiography at discharge and on follow-up visit: no significant differences in $\mathrm{EF}$, the number of patients had wall motion abnormalities was higher during follow-up compare to that at discharge. 225 bypass grafts were assessed: 141 were patent $(62.68 \%) ; 84$ were stenosed

\footnotetext{
* Trung tâm tim mạch, Bệnh viện E

**Trưòng ĐHY Hà Nọi, Khoa PT Tim mạch-Lồng ngưcc, BV Việt Đuic Ngườ chịu trách nhiẹm khoa học: GS.TS. Lê Ngoc Thành

Ngày nhận bài: 01/04/2018 - Ngày Cho Phép Đăng: 10/04/2018

Phản Biện Khoa học: GS.TS. Bùi Đức Phú PGS.TS. Đặng Ngoc Hùng
} 
(37,33\%). Bypass graft to coronary artery whose pre-operative stenosis was $\geq 95 \%$ had lower rate of stenosis $(p=0.009)$. Left internal mammary artery graft had the highest rate of patency, there was no differences between radial artery graft and saphenous vein graft $(\mathrm{p}<0.05)$. Patients undergoing coronary artery bypass graft surgery experienced clinical improvement. The most common cardiovascular complications during postoperative follow-up were: death, graft stenosis requiring intervention. Left internal mammary artery graft has the highest quality.

\section{I. ĐẠTT VẤN ĐỀ}

Phẫu thuật bắc cầu chủ vành là phương pháp điều trị kinh điển của bệnh hẹp động mạch vành do xơ vữa, có ưu điểm tái tưới máu lâu bền và được khuyến cáo lựa chọn trong những trường hợp tổn thương nặng nhiều động mạch, nhất là những trường hợp tổn thương cả 3 thân động mạch vành chính, tổn thương thân chung động mạch vành trái,... Mặc dù hiện nay can thiệp qua da ngày càng được chỉ định rộng rãi, nhiều nghiên cứu gần đây cho thấy phẫu thuật có lợi hơn so với can thiệp qua da ở nhóm bệnh nhân thương tổn nặng nhiều mạch. Nghiên cứu của chúng tôi đánh giá kết quả trung hạn phẫu thuật bắc cầu chủ vành cho nhóm bệnh nhân này.

\section{KẾT QUẢ NGHIÊN CÚU}

\section{1. Đặc điểm trước mổ:}

Bảng 3.1: Đặc điểm trước mổ

\begin{tabular}{|c|c|c|c|}
\hline \multicolumn{2}{|l|}{ Đắc điểm chung } & $\mathbf{n}$ & $\% \quad(n=93)$ \\
\hline \multicolumn{2}{|l|}{ Tiểu đường } & 20 & 21,51 \\
\hline \multicolumn{2}{|l|}{ THA } & 70 & $\mathbf{7 5 , 2 7}$ \\
\hline \multicolumn{2}{|l|}{ TBMMN } & 13 & 13,98 \\
\hline \multicolumn{2}{|l|}{ NMCT } & 20 & 21,74 \\
\hline \multicolumn{2}{|l|}{ Suy thận } & 5 & 5,38 \\
\hline \multirow{4}{*}{ BMI } & $<18,5$ & 8 & 8,6 \\
\hline & $18,5-23$ & 45 & 48,39 \\
\hline & $>23-27,5$ & 38 & 40,86 \\
\hline & $>27,5$ & 2 & 2,15 \\
\hline \multicolumn{2}{|c|}{ Đau thắt ngực ồn định } & 51 & 54,84 \\
\hline \multicolumn{2}{|c|}{ Đau thắt ngực không ôn định } & 42 & 45,16 \\
\hline \multicolumn{2}{|c|}{ NYHA III,IV } & 6 & 6,44 \\
\hline \multicolumn{2}{|l|}{ Mố cấp cứu } & 5 & $5,37 \%$ \\
\hline \multicolumn{2}{|l|}{ Mố bán cấp } & 13 & $13,98 \%$ \\
\hline
\end{tabular}




\subsection{Kết quả phẫu thuật}

Tử vong bệnh viện 6 (6,44\%). 87 bệnh nhân sống ra viện (93,56\%) hết đau thắt ngực. Tại thời điểm nghiên cứu: đau ngực tái phát 13/76 (17,11\%), không có bệnh nhân nào NYHA III, IV .

Bảng 3.2: Chức năng tâm thu thất trái trên siêu âm tim

\begin{tabular}{|c|c|c|c|c|}
\hline $\mathbf{E F}$ & $\begin{array}{c}\text { Trước mổ (1) } \\
(\mathrm{n}=93)\end{array}$ & $\begin{array}{c}\text { Ra viện (2) } \\
(\mathbf{n}=\mathbf{8 7})\end{array}$ & $\begin{array}{c}\text { Khám lại (3) } \\
n=76\end{array}$ & $\mathbf{p}$ \\
\hline $31-50 \%$ & $\begin{array}{c}22 \\
(23,66)\end{array}$ & $\begin{array}{c}10 \\
(11,49)\end{array}$ & n $\quad(\%)$ & \multirow{2}{*}{$\begin{array}{l}\mathrm{p}^{1-2}=0,03 \\
\mathrm{p}^{1-3}>0,05 \\
\mathrm{p}^{2-3}>0,05\end{array}$} \\
\hline$>50 \%$ & $\begin{array}{c}71 \\
(76,34)\end{array}$ & $\begin{array}{c}77 \\
(88,51)\end{array}$ & $11(14,47)$ & \\
\hline$\overline{\mathrm{X}} \pm \boldsymbol{S D}$ & $58,32 \pm 11,41$ & $59,2 \pm 9,45$ & $65(85,53)$ & $>0,05$ \\
\hline
\end{tabular}

Phân suất tống máu thất trái sau mổ được cải thiện có ý nghĩa ngay sau mổ ở nhóm bệnh nhân EF thấp trước mổ $(\mathrm{p}=0,03)$. Tại thời điểm khám lại sự khác biệt không có nghĩa thống kê.

Bảng 3.3: Rối loạn vận động vùng trên siêu âm tim

\begin{tabular}{|c|c|c|c|c|}
\hline Rối loạn vận động vùng & $\begin{array}{c}\text { Trước mổ (1) } \\
\mathbf{n ~ ( \% )}\end{array}$ & $\begin{array}{c}\text { Ra viện (2) } \\
\mathbf{n ~ ( \% )}\end{array}$ & $\begin{array}{c}\text { Khám lại (3) } \\
\mathbf{n}(\mathbf{\%})\end{array}$ & $\mathbf{p}$ \\
\hline \multirow{2}{*}{ Có } & 31 & 15 & 25 & \\
& $(33,33)$ & $(17,24)$ & $(32,89)$ & \multirow{2}{*}{$\mathrm{p}^{1-2}=0,01$} \\
Không & 62 & 72 & 51 & $\mathrm{p}^{2-3}=0,01$ \\
$(66,67)$ & $(82,76)$ & $(67,11)$ & \\
\hline Tổng số & $\mathbf{9 3}$ & $\mathbf{8 7}$ & $\mathbf{7 6}$ & \\
\hline
\end{tabular}

Trước mổ 31 bệnh nhân có rối loạn vận động vùng, sau mổ còn 15 trường hợp, không có trường hợp nào xuất hiện mới. Sự thay đổi có ý nghĩa thống kê $\left(\mathrm{p}^{1-2}=0,01\right)$. Tại thời điểm ra viện có 15 trường hợp còn rối loạn vận động vùng, sau 52 tháng theo dõi có 25 bệnh nhân. Số xuất hiện mới: 13. Số bệnh nhân có rối loạn vận động vùng tăng lên theo thời gian $\left(\mathrm{p}^{2-3}=0,01\right)$.

\section{Kết quả chụp cầu nối}

Tổng số 225 cầu nối được chụp kiểm tra: còn thông 141(62,67\%), hẹp tắc: 84/225 (37,33\%)

Bảng 3.4: So sánh tỉ lệ cầu nối còn thông ở 3 logai mạch ghép

\begin{tabular}{|c|c|c|c|c|}
\hline Mạch ghép Kết quả chụp & $\begin{array}{l}\text { Thông } \\
\text { n (\%) }\end{array}$ & $\begin{array}{c}\text { Hẹp tắc } \\
\text { n (\%) }\end{array}$ & $\begin{array}{c}\text { Tổng số } \\
\text { n (\%) }\end{array}$ & $\mathbf{p}$ \\
\hline 1. ĐMNTT & $49 \quad(84,48)$ & $9 \quad(15,52)$ & $58 \quad(100)$ & \multirow{3}{*}{$\begin{array}{l}\text { p1-3 }<0,05 \\
\text { p2-3 }<0,05\end{array}$} \\
\hline 2. ĐMQ & $18 \quad(52,94)$ & $16(47,06)$ & $34 \quad(100)$ & \\
\hline 3. TMHL & $74 \quad(56,64)$ & $59 \quad(44,36)$ & $133(100)$ & \\
\hline Tổng số & $141(62,67)$ & $84(37,33)$ & $225 \quad(100)$ & \\
\hline
\end{tabular}


Mạch ghép ĐMNTTcó tỉ lệ cầu nối còn thông cao hơn so với ĐMQ và $\mathrm{TMH}(\mathrm{p} 1-3<0,05)$. Không có sự khác biệt giữa mạch ghép ĐMQ và TMHL (p2-3<0,05).

Bảng 3.5: Hẹp - tắc cầu nối ở các phân nhóm hẹp mạch trước mổ

\begin{tabular}{|c|c|c|c|c|}
\hline $\begin{array}{l}\text { Mức độ } \\
\text { đích }\end{array} \quad \begin{array}{c}\text { Cầu nối } \\
\text { hẹp ĐMV }\end{array}$ & $\begin{array}{l}\text { Thông } \\
\text { n (\%) }\end{array}$ & $\begin{array}{c}\text { Hẹp tắc } \\
\text { n (\%) }\end{array}$ & $\begin{array}{c}\text { Tổng số } \\
\text { n (\%) }\end{array}$ & $\mathbf{p}$ \\
\hline$<95 \%$ & $\begin{array}{c}56 \\
(56 \%)\end{array}$ & $\begin{array}{c}44 \\
(44 \%)\end{array}$ & $\begin{array}{c}100 \\
(100)\end{array}$ & \multirow{2}{*}{0,009} \\
\hline$\geq 95 \%$ & $\begin{array}{c}41 \\
(77,36 \%)\end{array}$ & $\begin{array}{c}12 \\
(22,64 \%)\end{array}$ & $\begin{array}{c}53 \\
(\mathbf{1 0 0})\end{array}$ & \\
\hline Tổng số & $\begin{array}{c}97 \\
(63,40)\end{array}$ & $\begin{array}{c}56 \\
(36,60)\end{array}$ & $\begin{array}{c}153 \\
(100)\end{array}$ & \\
\hline
\end{tabular}

Cầu nối vào ĐMV hẹp $\geq 95 \%$ trước mổ có tỉ lệ tắc hẹp thấp hơn $(\mathrm{p}=0,009)$.

Các biến cố chính trong thò̀i gian theo dõi

Bảng 3.6: Các biến cố chính trong thò̀i gian theo dõi

\begin{tabular}{|l|c|c|}
\hline Các biến cố & $\mathbf{n}$ & $\mathbf{\%}$ \\
\hline Tử vong do nguyên nhân tim mạch & 6 & 7,06 \\
\hline Tai biến mạch não & 2 & 2,35 \\
\hline NMCT & 1 & 1,18 \\
\hline Mổ lại & 1 & 1,18 \\
\hline Can thiệp đặt giá đỡ ĐMV & 5 & 5,88 \\
\hline
\end{tabular}

Tử vong do nguyên nhân tim mạch, tái hẹp phải can thiệp là các biến cố thường gặp nhất.

\section{BÀN LUẬN}

\subsection{Cải thiện triệu chứng lâm sàng,} giúp người bệnh quay trở lại với các hoạt động đời thường là một trong những mục tiêu chính của bắc câu chủ vành. Kết quả nghiên cứu của cúng tôi cho thấy sau phẫu thuật triệu chứng lâm sàng thay đổi rõ rệt: tất cả các bệnh nhân còn sống sau mổ đều hết đau ngực ngay sau phẫu thuật, cải thiện triệu chứng suy tim. Sau hơn 4 năm theo dõi: 82,9\% bệnh nhân không có đau ngực tái phát. Nghiên cứu của Lorusso với thời gian theo dõi trung bình sau mổ $3,8 \pm 6$ năm (thay đổi từ 3 tháng -9 năm): thời điểm 4 năm sau mổ, tỷ lệ bệnh nhân suy tim NYHA
III, IV giảm từ 43\% trước mổ xuống 24\%; thời điểm 8 năm sau mổ tỷ lệ này là $35 \%$ [1]. Bax và cộng sự cho thấy cải thiện tình trạng suy tim sau mổ với độ NYHA thay đổi từ 3,26 $\pm 0,7$ trước mổ xuống 1,6 \pm 0,6 sau mổ 2 năm [2]. Đau thắt ngực là triệu chứng điển hình của bệnh và cũng là lý do chính người bệnh đi khám. Cải thiện triệu chứng đau ngực sau phẫu thuật, tỉ lệ tái phát theo thời gian là vấn đề được quan tâm trong phần lớn các nghiên cứu về kết quả $\mathrm{BCCV}$. Đau thắt ngực tái phát thường là triệu chứng lâm sàng báo hiệu xuất hiện mới vùng cơ tim thiếu máu. Nguyên nhân có thể do phẫu thuật chưa tái tưới máu đủ các nhánh, hẹp tắc cầu nối, hoặc hẹp 
ĐMV tiến triển. Kết quả của Fihn và cộng sự: 80\% bệnh nhân không bị đau ngực tái phát sau 5 năm phẫu thuật [3].

\section{2 Đánh giá phục hồi chức năng co} bóp cơ tim trên siêu âm: Thiếu máu cơ tim gây rối loạn về chức năng sinh lý và biến đổi giải phẫu của cơ tim: khả năng co bóp của cơ tim giảm, rối loạn vận động vùng. Hậu quả nặng nhất của tình trạng thiếu máu gây hoại tử tế bào cơ tim không hồi phục. Việc tái tưới máu sẽ giải quyết tình trạng suy giảm chức năng của tế bào, cải thiện khả năng co bóp cơ tim. Có nhiều phương pháp đánh giá sự hồi phục này: siêu âm tim, chụp cộng hưởng từ, xạ đồ cơ tim, thông tim chụp buồng thất trái. Trong lâm sàng, siêu âm tim được sử dụng phổ biến nhất, đánh giá sự thay đổi chức năng có bóp cơ tim trên siêu âm tim qua thành ngực thông qua 2 thông số: phân suất tống máu thất trái $(\mathrm{EF})$ và rối loạn vận động vùng. Chỉ số bình thường $\mathrm{EF}>50 \%$. Theo Jeroen $\mathrm{J}$ Bax, phân suất tống máu thất trái được coi là cải thiện khi tăng $\geq 5 \%$ [2].

Phần lớn các nghiên cứu đều cho thấy nhóm bệnh nhân có EF giảm trước mổ đều có sự cải thiện sau khi được phẫu thuật. Hamad phẫu thuật cho các bệnh nhân có EF trung bình trước mổ 0,32 $\pm 0,06$; 6 tháng sau mổ: 44,0 $\pm 4,0$; sau 4 năm: $0,46 \pm 0,02$ [4]. Lorusso và cộng sự với 120 bệnh nhân EF trung bình $28 \% \pm 9$ (thay đổi $10-$ $40 \%$ ) trước mổ, kết quả ngay sau mổ EF $40 \pm 2 \%$ $(\mathrm{p}<0,01)$. Tuy nhiên trong các thời điểm theo dõi xa chỉ số này ổn định ở mức thấp hơn so với thời điểm ngay sau phẫu thuật: sau 3 tháng $33 \pm 9 \%$, sau 12 tháng $32 \pm 8 \%$, sau 8 năm $30 \pm 9 \%$. [1].

Chức năng vận động vùng được đánh giá qua thang điểm mô tả vận động vùng cơ tim. Hiệp hội tim mạch Hoa Kỳ chia 17 vùng vận động thất trái, với thang điểm ước lượng như sau: 1 - vận động bình thường; 2- giảm vận động; 3- không vận động; 4- vận động nghịch thường; 5- cơ tim bị phồng. Chỉ số điểm vận động toàn thể (Wall motion score index: WMSI) được tính trung bình điểm vận động của 17 vùng. Chỉ số bình thường là 1 ; từ $1,1-$ 1,9 vùng nhồi máu nhỏ; $\geq 2$ : nguy cơ biến chứng [5], [6].

Nghiên cứu của Bax và cộng sự cho thấy tới $90 \%$ vùng cơ tim được đánh giá còn sống trước mổ bằng siêu âm tim gắng sức với Dobutamin cải thiện co bóp sau mổ, $75 \%$ vùng cơ tim được đánh giá không còn sống bằng phương pháp này không cải thiện co bóp sau phẫu thuật [2].

4.3. Kết quả chụp cầu nối: Sự thông suốt của cầu nối là một trong những yếu tố ảnh hưởng quyết định đến thành công của phẫu thuật và chất lượng cuộc sống người bệnh sau mổ: cải thiện các triệu chứng lâm sàng, cận lâm sàng, $\mathrm{NMCT}$, tử vong, tình trạng đau ngực tái phát, sống còn sau mổ,... Hẹp tắc cầu nối sau mổ chịu ảnh hưởng của nhiều yếu tố: loại mạch ghép được sử dụng, kỹ thuật làm miệng nối, mức độ hẹp mạch vành đích, bệnh nền và các yếu tố nguy cơ...Ở đây chúng tôi đề cập đến một số yếu tố liên quan đến phẫu thuật. Yếu tố mạch ghép: *Mạch ghép ĐMNT: ĐMNTT được sử dụng phổ biến nhất làm cầu nối vào ĐMLTT do vị trí thuận lợi và tính chất quan trọng chi phối vùng cơ tim của ĐMLTT. ĐMNT được chứng minh là cầu nối có chất lượng tốt với tỉ lệ còn thông theo thời gian cao nhất trong các loại mạch ghép. Nghiên cứu của Arima tại Nhật Bản công bố 2005 tỉ lệ còn thông của ĐMNTT sau $1,5,10$ và 15 năm lần lượt là: 97.6\%, 97.6\%, 95.0\%, và $95.0 \%$ [7]. Theo tổng kết của Taggart 90-95\% cầu nối ĐMNT còn thông tốt sau 10-15 năm [8]. Các nghiên cứu về mô học đã lý giải cho chất lượng mạch ghép ĐMNT tốt hơn hẳn các loại mạch ghép khác: cấu trúc thành động mạch 
động mạch chịu áp lực cao, sự liên tục của lớp nội mạc làm ngăn ngừa lắng đọng lipoprotein ở lớp dưới nội mạc vì vậy ĐMNT rất ít bị xơ vữa. Mặt khác,lớp nội mạc của ĐMNT tiết ra nhiều chất giãn mạch (endothelium-derived relaxing factor-EDRF) và siêu phân cực (endotheliumderived hyperpolarizing factor - EDHF). Các chất này đóng vai trò quan trọng trong việc ức chế ngưng tập tiểu cầu, ngăn ngừa hẹp tắc mạch theo thời gian. Đồng thời ĐMNT cũng ít co thắt hơn các động mạch khác [9]. *Mạch ghép TMHL: tỷ lệ hẹp tắc cao hơn so với mạch ghép động mạch. Nghiên cứu của Sabik: tỷ lệ tắc hẹp sau 1 năm của TMHL: $10 \%-20 \%$, từ năm thứ 2 5 cộng thêm $5 \%-10 \%$, năm thứ 6 - 10 cộng thêm $20 \%$ to $25 \%$. Sau 10 năm chỉ còn khoảng $50 \%$ mạch ghép TMHL còn thông [10]. Nhược điểm của TMHL thành mạch vốn chỉ chịu áp lực thấp, khi sử dụng làm cầu nối, thành TMHL phải chịu áp lực động mạch (> 10 lần áp lực sinh lý của tĩnh mạch). Sự thay đổi đột ngột này gây tổn thương nội mạc, dẫn tới hiện tượng ngưng tập tiểu cầu hình hành huyết khối gây tắc cấp cầu nối, xảy ra sớm sau mổ. Nội mạc bị thương tổn, tăng ngưng tập tiểu cầu cũng dẫn tới việc tăng sinh nội mạc, xơ vữa thành tĩnh mạch đã bị động mạch hóa làm hẹp tắc cầu nối. *Mạch ghép $Đ M Q$ : được sử dụng lần đầu tiên bởi Carpentier vào năm 1971, sau đó bị gián đoạn do tỉ lệ tắc sớm cao (30-50\%) hậu quả của co thắt mạch và tăng sinh nội mạc [11]. Tuy nhiên năm 1992, Acar và cộng sự nhận thấy nhiều cầu nối ĐMQ còn hoạt động tốt sau một thời gian dài. Ông cùng các đồng nghiệp sử dụng lại ĐMQ làm cầu nối. Cùng với những hiểu biết về cấu cấu trúc mô học của mạch, sử dụng các thuốc chống co thắt, thay đổi kỹ thuật lấy mạch dẫn tới việc giảm tỷ lệ tắc cầu nối. ĐMQ được sử dụng lại ngày càng phổ biến, nhiều nghiên cứu cho thấy lợi ích của ĐMQ làm mạch ghép thứ 2 so với TMHL hoặc sử dụng thêm ĐMNT phải. Mức độ hẹp mạch trước mổ: Sự thông suốt của cầu nối có liên quan đến mức độ hẹp của ĐMV đích trước mổ do có hiện tượng tranh chấp dòng máu lưu thông tự nhiên trong mạch vành đích qua chỗ hẹp và dòng máu đi từ mạch ghép qua miệng nối. Dòng tranh chấp tỷ lệ nghịch với mức độ hẹp của ĐMV đích. Hiện tượng này thường quan sát thấy ở gần vị trí miệng nối tận bên, còn được gọi là hiện tượng dòng chảy ngược: khi chụp chọn lọc cầu nối sẽ không thấy dòng chảy qua miệng nối xuống ĐMV nhưng thấy dòng chảy ngược từ ĐMV qua miệng nối vào mạch ghép khi chụp xâm lấn chọn lọc ĐMV đích tương ứn. Nghiên cứu của Nakajima trên 570 bệnh nhân với 2083 cầu nối được chụp kiểm tra, tỉ lệ có dòng tranh chấp 2,4\%; mức độ hẹp < 75\% ở ĐMVP hoặc ĐMM có ý nghĩa dự báo nguy cơ tắc hẹp cầu nối do dòng tranh chấp [12]. Dòng tranh chấp gây hiện tượng dòng chảy rối, thay đổi áp lực lên thành mạch giảm lưu lượng dòng chảy trong mạch ghép dẫn tới nguy cơ hình thành cục máu đông, tăng sinh nội mạc gây tắc hẹp miệng nối. Dòng tranh chấp hay gặp ở cầu nối động mạch hơn cầu nối tĩnh mạch. Cầu nối động mạch có lớp cơ trơn, có cơ chế tự điều hòa: dòng máu lưu thông trong cầu nối sẽ theo nhu cầu, khi ĐMV hẹp nhiều, nhu cầu tăng nhiều, cầu nối động mạch sẽ giãn ra để máu lưu thông dễ dàng. Ngược lại, khi hẹp ít (nhu cầu giảm), cầu nối động mạch sẽ co lại để giảm lưu lượng, hậu quả mạch ghép sẽ bị tắc nếu tình trạng co mạch kéo dài. Điều này thấy rõ ở các động mạch có lớp cơ trơn dày như động mạch quay. Khuyến cáo của một số tác giả cho thấy không nên sử dụng ĐMQ làm cầu nối khi mức độ hẹp $<90 \%$, có nghiên cứu cho điểm ranh giới này $<75 \%$ [13]. Theo Buxton mức độ hẹp $<70 \%$ của hệ ĐMV trái, $<90 \%$ của ĐMVP trong trường hợp 
ĐMVP ưu thế, là yếu tố nguy cơ của hẹp tắc cầu nối động mạch [14]. Kết quả nghiên cứu của chúng tôi: tỉ lệ hẹp tắc cầu nối vào các ĐMV hẹp $\geq 95 \%$ đường kính lòng mạch thấp hơn có ý nghĩa so với các ĐMV hẹp < 95\%.

Các biến cố tim mạch: hay gặp tái hẹp phải can thiệp lại, tử vong. Trong nghiên cứu này tử vong $9 / 85(10,59 \%)$ trường hợp trong thời gian theo dõi, trong đó 6 bệnh nhân $(7,06 \%)$ do nguyên nhân tim mạch. Theo Trường Môn Tim Mạch/Hội Tim Mỹ(năm 2004), tính chung trong BCCV, tỉ lệ sống còn sau 5 năm là $92 \%$, sau 10 năm $81 \%$.

Kết quả nghiên cứu có 6 bệnh nhân tái hẹp phải can thiệp lại $(7,06 \%)$. BCCV lần đầu ở những bệnh nhân hẹp $\mathrm{TC}$, tổn thương 3 thân ĐMV, tổn thương 2 thân ĐMV trong đó có đoạn gần ĐMLTT được chứng minh là có kết quả tốt hơn so với can thiệp đặt giá đỡ ĐMV. Tuy nhiên lợi ích của phẫu thuật lại ở những trường hợp này so với điều trị nội khoa, đặt giá đỡ ĐMV còn chưa rõ ràng. Có nghiên cứu cho thấy những trường hợp xuất hiện thiếu máu cơ tim trở lại ở vùng cơ tim do cầu nối vào ĐMLTT cấp máu làm giảm tỷ lệ sống còn sau mổ. Các tác giả khuyến cáo khi có hẹp $\geq 50 \%$ cầu nối vào ĐMLTT thì nên phẫu thuật lại. Biện pháp can thiệp đặt giá đỡ ĐMV được áp dụng trong năm đầu tiên sau phẫu thuật [15]. Những trường hợp thiếu máu vùng cơ tim không do ĐMLTT cấp máu không thấy lợi ích của việc phẫu thuật lại.

\section{KẾT LUẬN}

Phẫu thuật bắc cầu chủ vành cải thiện rõ rệt các triệu chứng đau thắt ngực và mức độ suy tim. Mức độ thông của cầu nối theo thời gian liên quan chặt chẽ với yếu tố mạch ghép (mạch ghép động mạch ngực trong trái có chất lượng tốt nhất, với tỉ lệ cầu nối còn thông cao nhất so với mạch ghép động mạch quay và tĩnh mạch hiển lớn) và tỉ lệ thuận với mức độ hẹp của động mạch vành đích trước mổ: cầu nối vào các ĐMV hẹp $>95 \%$ trước mổ có tỉ lệ hẹp tắc thấp hơn.

\section{TÀI LIỆU THAM KHẢO}

1. Lorusso R., La Canna G., Ceconi C. et al (2001), Long-term results of coronary artery bypass grafting procedure in the presence of left ventricular dysfunction and hibernating myocardium, Eur J Cardiothorac Surg, 20(5).937-948.

2. Bax Jeroen J., Poldermans Don, Elhendy Abdou et al (1999), Improvement of left ventricular ejection fraction, heart failure symptoms and prognosis after revascularization in patients with chronic coronary artery disease and viable myocardium detected by dobutamine stress echocardiography,Journal of the American College of Cardiology, 34(1).163-169.

3. Hawkes A. L., Nowak M., Bidstrup B. et al (2006), Outcomes of coronary artery bypass graft surgery,Vasc Health Risk Manag, 2(4).477-484.

4. Soliman Hamad M. A., Tan M. E., van Straten A. H. et al (2008), Long-term results of coronary artery bypass grafting in patients with left ventricular dysfunction, Ann Thorac Surg, 85(2).488-493.

5. Esmaeilzadeh M., Parsaee M. ,Maleki M. (2013), The role of echocardiography in coronary artery disease and acute myocardial infarction, J Tehran Heart Cent, 8(1).1-13.

6. Cerqueira M. D., Weissman N. J., Dilsizian V. et al (2002), Standardized myocardial segmentation and nomenclature for tomographic imaging of the heart. A statement for healthcare professionals from the Cardiac Imaging Committee of the Council on Clinical Cardiology of the American Heart Association, Circulation, 105(4).539-542. 
7. Arima M., Kanoh T., Suzuki T. et al (2005), Serial angiographic follow-up beyond 10 years after coronary artery bypass grafting, Circ J, 69(8).896-902.

8. Taggart D. P(2013), Current status of arterial grafts for coronary artery bypass grafting. Ann Cardiothorac Surg, 2(4), 427-430.

9. Otsuka F., Yahagi K., Sakakura K. et al (2013), Why is the mammary artery so special and what protects it from atherosclerosis?,Ann Cardiothorac Surg, 2(4).519-526.

10. Sabik J. F, (2011). Understanding saphenous vein graft patency. Circulation, 124(3), 273-275.

11. Acar C., Jebara V. A., Portoghese M. et al (1992), Revival of the radial artery for coronary artery bypass grafting,Ann Thorac Surg, 54(4).652-659; discussion 659-660.

12. Nakajima H., Kobayashi J., Tagusari O. et al (2006), Angiographic flow grading and graft arrangement of arterial conduits, J Thorac
Cardiovasc Surg, 132(5).1023-1029.

13. Buxton B. F., Hayward P. A., Newcomb A. E. et al (2009), Choice of conduits for coronary artery bypass grafting: craft or science?,Eur J Cardiothorac Surg, 35(4).658-670.

14. Buxton B. F. ,Hayward P. A. (2013), The art of arterial revascularization-total arterial revascularization in patients with triple vessel coronary artery disease, $A n n$ Cardiothorac Surg, 2(4).543-551.

15. Scanlon P. J., Faxon D. P., Audet A. M. et al (1999), ACC/AHA guidelines for coronary angiography: executive summary and recommendations. A report of the American College of Cardiology/American Heart Association Task Force on Practice Guidelines (Committee on Coronary Angiography) developed in collaboration with the Society for Cardiac Angiography and Interventions, Circulation, 99(17). 2345-2357. 